\title{
The Philosophy and Possible Inadequacies of Crises Governance: Lessons from a Recent Book
}

\author{
Dimitris Konstantinos Kioukias \\ Department of Business and Organizations Administration, School of Social Sciences, Hellenic Open University, Patras, \\ Greece
}

\section{Email address: \\ kioukias@hotmail.com}

\section{To cite this article:}

Dimitris Konstantinos Kioukias. The Philosophy and Possible Inadequacies of Crises Governance: Lessons from a Recent Book. International Journal of Law and Society. Vol. 3, No. 3, 2020, pp. 102-105. doi: 10.11648/j.ijls.20200303.14

Received: May 12, 2020; Accepted: July 3, 2020; Published: July 13, 2020

\begin{abstract}
This short case is based on the author's book "Governing Really?" which inserts into policy analysis some new philosophical, methodological and practical insights. Whereas the book includes analyses of quite a few policy areas, this case study delimits its investigation to unexpected events-crises. While purely managerial approaches to problem solving rest on some quantifiable evaluation criteria, a more classical rule of law approach usually focuses on causes and punishment of a crime. Even though in the case of "natural disasters" this is a difficult work, among others because they are quite internationalized, the casualties that hit the population are such that lack of investigation of this sort will prove to be both unfair and dangerous. The paper suggests that preventive work can be done in the area of education and culture, aiming at reintroducing more logical argumentation at the expense of postmodern irrationalism and various techniques inspired by it. If postmodern revisionism has the merit of encouraging more pluralistic approaches to policy making, we must keep alert about its relativism and its tendency to transmit (to the media and the laws among others) insignificant stories, or a fear about description. Therefore, so the argument goes, a policy maker must take into account "great" ideas too, as ideas guide any kind of thought, including materialist mental artifacts. At the end of the day one of selected ideas will fit a case in question. Accordingly, effective tackling of natural disasters may well rest on managerialism, as it has happened in the historical past, but must choose a good governing idea too, avoiding routine automatic, or "silent" solutions.
\end{abstract}

Keywords: Governing, Unexpected Crises, Managerialism, Legal Approaches, Materialism, Postmodernism, Ideas

\section{Introduction}

In the Fall of 2019 I had the opportunity to publish a new book on public policy formation [1]. A few months later the Covid-19 Pandemic burst out, a much worst disaster than other late epidemics, or similar catastrophes such as floods, sea pollution, fires, or earthquakes. Though one cannot see them as a product of intention, it is nevertheless true that much emphasis was placed on their good management and even the proper systems of governance. This is to no surprise: in the past scarcity of food, or water had been politicized and made an (international) "rếgime" $[2,3]$. In an era of extreme internationalization all "power resources" have become of political concern. Traditional medical issues have been transformed into international politics, or, at least, comparative politics-WHO as an international organizationumbrella is characteristic of the development. Thus, it is commonly heard that the pandemic profoundly affected national and global economies. If an illness is so intrusive as to manage to blur the boundaries between health and (economic) politics as well as domestic and international politics, we have a point that illustrates the previous arguments. We then have to define accurately the policy issue in question and choose the right administrative department to handle the issue. To cite an additional example from the book, immigration issues can be both handled by competent immigration authorities and the foreign ministry. Such choice, of course, also depends upon the predominant policy philosophy.

\section{The Managerial Approach vs. Traditional Juridical Approaches}

As a matter of fact, a managerial approach is now quite common, especially when it comes to great crises-natural 
disasters. We often find out that such issues are viewed more as regulatory ones than a kind of a crime. They look like a puzzle, a game. Thus, we tend to search less for the primary suspect (cause) than the timely response of the various administrative levels involved. For instance, we care less for the question of who might have set a fire than how competent authorities have reacted. We value ends that is, much more than causes, something connected to the concept of "results oriented management" [4, 5] much more than "legality" which is more affiliated to causes (for instance, a law which is to be introduced to the parliament must be officially accompanied by a "causal report").

Moreover, as competent authorities are now multiple, because of an enforcement of the doctrine of the multi-level government, guilt becomes quite diffuse, as risk society theories had suggested [6] and, hence, non-attributable (a characteristic feature of a puzzle). We may note here that the reorganization of the state along different levels was not meant as an enterprise on less responsibility. It rather aimed at more organizational specialization to achieve a greater degree of problem-solving capacity. The whole issue is deeply scientific, for, in science too, too much specification often amounts to something close to agnosticism. Take also the case of team work. Quite often good opinions are suppressed by mean opinions, because they manage to become popular, or because they enjoy greater predeliberation privileges. Great popularity is nevertheless not necessarily the best solution. Instead, clearly organized teams, e.g. by proven experience and capacity will better approach difficult problems such as critical conditions. Yet, such selection presupposes good work across the whole spectrum of education. This is the realm where evaluation criteria are learnt. Thus, an educational system which promotes too much team work, specialization, lack of organizing knowledge according to basic standards of significance, etc., is bound to prepare for less responsibility and awareness of the important issues. It is quite of a paradox that in an era of global awareness and "intrigue learning" we have become so indifferent and irresponsible. It seems that all this vast network of warnings, precautions, or threats is unsuitable for making us better prepared for critical problems. In my view, besides the problems of evaluation, the reason for this malaise lies in our transforming our reality into a set of games, as noted above. That is probably why much of the TV time is absorbed by numerous games. Here it is rather wrongly assumed that through games and tests we learn better, as we are supposed that we easily internalize the proper messages. While there is a seed of truth in the old belief that myths and games teach, too much playing may make people simply childish. It is equally true that myths and games are learning methods for teens; they are not made for all ages. As we move up the ladder of knowledge, we transcend each stage, often without return, for we often feel that what we conquered yesterday was just history, or a kind of a joke. In the same way, we often laugh at our past "achievements"; were we the same people as those ones seen in the photograph? This kind of demythologization, greatly favored by technological progress, runs against myth creation. Why then do we insist so much in making up new stories?

I do not know if such examples give credit to the allegation that there is now "a modernist hyper-regulatory state that colonizes social life" [7]. Nor can I reassert the claim that we have got a "therapeutical state" which attempts to regulate lifestyle, through excessive social care and clever intrusion in private life [8]. What is more probable is the fact that natural disasters, or economic and social crises, have become more common worldwide than it used to be the case. As a result both states and the international community have greatly focused on the management of unexpected phenomena and therefore systems of government have been affected accordingly. For example, an aura of millenarianism which has spread over the world may have contributed to a preference for "consensus political systems", often exemplified by the proliferation of independent authorities and other similar inspection agencies. As a matter of fact, surveillance mechanisms are taking the institutional middle ground, sometimes at the expense of classical parliamentary institutions. This development is matched by a blurring of traditional ideological lines, with a fresh focus on preventive mechanisms and solidarity based ideas which largely distant themselves from the classical law which was based on the individual and the relationships he happened to build. As we mentioned above, according to the risk society theories, attachment of guilt and punishment became much more diffuse. Indeed, a grey area of covered anomie seems to have been created just at the same time all these surveillance authorities, or measurement agencies, were established and functioned. It must be noted in this conjunction that "governing by measurement", if we may say so, is another feature of modern governance serving among others the same purpose, i.e. surveillance. For, calculation has to do with putting in order and thereby extracting a great degree of accountability. This is similar to marking students' papers and other assignments. Naturally, betterment is also served by ranking techniques, save for the case these become an end in itself. Thus, systematic announcement of public debt reduction does not help to alleviate the real poor income of the mass. We understand though that daily political work is transferred unmediated to the public through the media and the internet.

Order now by itself is always desirable. Besides, in international politics the quest for a "new order" is a very common chapter [9]. Order by all means, however, is rarely asked, at least by civilized parties. Even if traditional institutions and their cadres are less popular (according to opinion polls), demands for law free societies have not been observed. After all, all new institutions are law based, whereas economic decisions are interwoven with new legal regulations.

On the other hand, the instrumentality of law is discussed anew. This fresh impetus on the issue might perhaps have been aided by the modern vast proliferation of legal regulations. All this state of urgency, social protection and crime prevention must have been largely conducive. 


\section{Some Notes on Proper Scientific Inquiry into Administrative Matters}

Having said that, we realize that law is not a mere product of economic-class relationships; nor is a material world ever in a position to dictate ideas and laws to politicians and experts. Animals and woods are to be protected by us via laws, or may be destroyed by some of us. Whatever dialogue we may establish with nature is our dialogue; it is us who "run the show". Trees never speak, but simply point-to paraphrase a dictum of pre-Socratic Heraclitus (he said something similar about the prophets) [10]. If God is not a daily advisor, Nature is equally speechless; we make decisions about men and women, majorities and minorities, relying on ideas including materialist ones. Marxism, or determinist theories about birth and evolution of life and the universe are still mental artifacts. For, at least in so far as the latter are concerned, they are based on the idea that matter produces further matter and, finally, life [11]. "In other words, all theories are simply ideas that compete to become recognized as the truth" [12]. If this sounds like a postmodern credo, it does stands out, in our view, as a good starting point. We cannot, of course, accept its subjectivism.

To decide well we must listen to what "natural law" and written human work have to say. In a number of policy areas we have to take the precedent into account. A good student may become a good reformer. We find then difficult to change the order of things, to reinvent the wheel. Good legislators cannot build a good community "from above", that is refusing past knowledge altogether. More importantly, a policy maker will often be faced with multiple dilemmas, as plural principles may compete over the right solution to a public issue. Though a common managerial solution is usually preferable, bypassing the real governing principle of the issue sounds like a "call" for repetition. Choice of the each time proper issue area is equally important. If, for instance, migration is not just a domestic issue, a disease of mass scale may also be an international issue. In an era of continuous internationalization as well as increasingly blurred levels of governance such considerations gain additional importance. It is quite common nowadays that, when a major fire, or an epidemic, bursts out, each level tries to transfer responsibility to some other level. Yet, when a situation has been clearly defined and the key principle has been clearly spelled out, such inadequacies may be avoided. This is, of course, not to deny the perils of internationalization which is sometimes domesticated as well. "The name of the bow's work" [13] is too difficult to spell.

On the other hand, to manage to speak with transparency and precision is exactly what is lacking. A specter of mysticism, virtual, or parallel, reality and game play seems to haunt the systems of governance. Probably the great influence of mass media must account for that. Just like in Homer's Odyssey, in which shadows and sounds were artificially multiplied, real and common things and relationships are enormously augmented by the camera. One may find then extremely difficult to weigh accurately such common goods as peace and violence, men and women, youngsters and elders, education level and pay. Despite this emphasis on quantifiable evaluation, because of extreme coverage, measurement is getting very difficult. Instances of such failure may be found in the afore-mentioned book.

A distorted view of the public issues is nevertheless not owed to augmentation of small issues by the media solely. Because of the supposed arrogance of some "grand narratives", rationalism was attacked by some postmodern conceptions which focused on "small narratives". Rationalism as epics though is one thing, thinking in logical measure is another. As a result too much emphasis was placed on insignificant stories on the pretext that they carried a quite didactic hidden message. The arts and the media were very much influenced by this current. This is one reason why we have claimed that postmodernism virtually reiterated some methods of modernism [1]. What is more important is the message, not the form. Unfortunately, some useful parables of this sort were transformed into a great current which naturally influenced law making too. Yet, form is equally important, especially the precise form of a legal enactment. To stick too much to the "message" is like favoring abstract penalties.

\section{Conclusion}

A managerial approach to the government of unexpected events with a mass destruction capacity is undoubtedly indispensable, at least at the stage of "attack". Let it not be forgotten that at the peak of air bombardment during the World War II urgent measures for the population were equally important as military defense and reprisals. The "war economy" is said to have greatly been conducive to the building of the post war welfare state [14].

On the other hand, government in the full sense of the term must care about causes and true results too. Unless natural disasters are equaled to real warfare-we have indeed witnessed such views lately-a good government cannot be content with efficient management which limits casualties. This is indeed acceptable in true war. Even so, quite often the end of war was accompanied by punishing the aggressors and their domestic collaborators; courts would then take over. Return to normalcy meant the rehabilitation of public order, the rule of law and, hence, personalization of the crime, as it was the case with post-war European countries [15].

Yet, as in the case of blind blows, also discussed in the book under the title of "terrorism", natural disasters are nonattributable. If they must be connected to some kind of war, they must be considered to fall into the non-conventional war category. Still, national managerial solutions, even under the coordination of international institutions, however marked by excellent performance rates-as lately in Greece- leave much to be desired. We tend to believe and argue that a global educational response aiming at a rejection of irrationalism at various corners of the society is a step forward to a better international order. While it may be the case that not everything can be told, extreme hinting, on the other hand, 
only helps to burry another issue in the row.

I hope that such ideas can be multiplied in a lengthier treaty (the book), even though not by themselves, that is without an author. But, let be optimistic about the future, for, who knows, we may manage to make ideas too automatically generating more ideas and, finally, a book (...).

\section{References}

[1] Kioukias, D. (2019), Governing Really? An Essay on the Philosophy and Some Inadequacies of Public Policy, Lambert Academic Publishing.

[2] Kegley W. C \& Wittkpopf, E. R. (1989), World Politics: Trend and Transformation, $3^{\text {rd }}$ edition, New York, St. Martin's Press, p. $268 \mathrm{ff}$.

[3] Donelan, M., "States, Food and the World Common Interest" in C. Navari, ed., The Condition of States (1991), Buckingham: Open University Press, p. 216 ff.

[4] Kioukias, D. (2007), An Introduction to the Social States, Comparative Analyses and Practical Philosophy, Athens: I. Sideris, p. 169 (in Greek).

[5] Freeman, R. (2000), The Politics of Health in Europe, Manchester: Manchester University Press.

[6] Beck, U. (1996), The Invention of the Political, Athens: Nea Synora-A. Livani (in Greek).
[7] Radaelli, C. (2007), "Whither Better Regulation for the Lisbon Agenda?", Journal of European Public Policy, vo. 14, no. 2, pp. 190-207.

[8] Fitzpatrick, M. (2001), The Tyranny of Health: Doctors and the Regulation of Lifestyle, London: Routledge.

[9] For example, in the classical textbook Spero, J. E. (1985), The Politics of International Economic Relations, $3^{\text {rd }}$ edition, London, St. Martin's Press, ch. 10.

[10] Kioukias, D. (2014), "The Soul and its Vapors " in Rythms Philosophimata 2011-2014, ebook, Google \& Apple (in Greek).

[11] Grammatikakis, G. (2014), Vereniki's Hair, new revised edition, Herakleio: Panepistemiakes Ekdoseis of Crete (in Greek).

[12] Senior, M. \& Viveash, B. (1998), Health and Illness, London, McMillan, p. 326.

[13] Heraclitus (2010), All the Works, transl. by T. FalkosArvanitakis, Thessaloniki: Zitros.

[14] Hobsbawm, E. (1994), Age of Extremes, The Short Twentieth Century, London, Michael Joseph, pp. 46-47.

[15] De Gaulle, C. (2020), Memoires de Guerre, transl. by D. P. Kostelenos, Athens, Govostis/To Vima, p. $680 \mathrm{ff}$. 